\title{
Número necessário de experimentos para a análise de agrupamento de cultivares de feijão
}

\author{
Number of necessary experiments for the cluster analysis in common bean cultivars
}

\author{
Alberto Cargnelutti Filho ${ }^{\text {I* }}$ Nerinéia Dalfollo Ribeiro ${ }^{\mathrm{I}}$ Evandro Jost $^{\mathrm{II}}$
}

\section{RESUMO}

O objetivo deste trabalho foi determinar o número de ambientes (experimentos) necessários para a identificação de cultivares de feijão (Phaseolus vulgaris L.) divergentes por meio de análise de agrupamento, com base em características de produção, fenologia e morfologia. Para tanto, 13 cultivares de feijão foram avaliadas em nove experimentos conduzidos em Santa Maria, Estado do Rio Grande do Sul (latitude 29\%42S, longitude $53^{\circ} 49 \mathrm{~W}$ e $95 \mathrm{~m}$ de altitude), entre os anos agrícolas de 2000/2001 e 2004/2005. Foi utilizado o delineamento aleatorizado em blocos, com três repetições. Foram avaliados os caracteres produtividade de grãos, número de vagens por planta, número de sementes por vagem, massa de cem grãos, população final de plantas, número de dias da emergência ao florescimento, número de dias da emergência à colheita, altura de inserção de primeira vagem, altura de inserção de última vagem e grau de acamamento. Na região da depressão central do Estado do Rio Grande do Sul, Brasil, sete e seis experimentos são suficientes para identificar cultivares de feijão divergentes, por meio dos métodos de agrupamento hierárquico de Ward e de otimização de Tocher, respectivamente, quanto às características de produção, fenologia e morfologia.

Palavras-chave: Phaseolus vulgaris L., distância generalizada de Mahalanobis, divergência genética.

\section{ABSTRACT}

The objective of this research was to determine the number of environments (experiments) that were necessary to identify the diversity in common bean cultivars (Phaseolus vulgaris L.), by cluster methods based on productive, phenologic and morphologic traits. Thirteen common bean cultivars were evaluated in nine experiments conducted in Santa Maria, in Rio Grande do Sul State, Brazil (latitude $29^{\circ} 42^{\prime}$ S, longitude $53^{\circ} 49^{\prime} \mathrm{W}$, altitude $95 \mathrm{~m}$ ) in the agricultural years of 2000/ 2001and 2004/2005. Randomized blocks design with three replications was installed to evaluate the following characters: grain yield, number of pods per plant, number of seeds per pod, weight of 100 grains, final population of plants, number of days of the emergency to flowering, number of days of the emergency to harvest, height of first pod insertion, height of the final pod insertion and degree of the down. In the central depression region of Rio Grande do Sul State, Brazil, seven and six experiments are sufficient to identify the diversity in common bean cultivars, by hierarchical methods of the Ward and optimizing Tocher, respectively, for productive, phenologic and morphologic traits.

Key words: Phaseolus vulgaris L., Mahalanobis distance, genetic diversity.

\section{INTRODUÇÃO}

A inferência sobre a divergência genética em um grupo de genitores pode ser de natureza quantitativa e preditiva. Na primeira, citam-se as análises dialélicas, que possibilitam determinar a capacidade geral e a capacidade específica de combinação e a heterose manifestada nos híbridos. No entanto, a necessidade de avaliações de $\mathrm{p}$ genitores e de todas as suas combinações híbridas $\mathrm{p}(\mathrm{p}-1) / 2$, aliada ao fato de que, em algumas culturas, a polinização manual é onerosa, difícil de ser executada e com pouca probabilidade de êxito na obtenção de semente híbrida, pode inviabilizar o estudo, principalmente quando o valor de p é elevado (CRUZ \& REGAZZI, 1997; CRUZ IDepartamento de Fitotecnia, Centro de Ciências Rurais (CCR), Universidade Federal de Santa Maria (UFSM), 97105-900, Santa
Maria, RS, Brasil. E-mail: cargnelutti@pq.cnpq.br. *Autor para correspondência.

IIPrograma de Pós-graduação em Agronomia, UFSM, Santa Maria, RS, Brasil. 
\& CARNEIRO, 2003). Nesse contexto, por dispensarem a obtenção prévia das combinações híbridas, destacamse os métodos preditivos da divergência entre genitores, que se baseiam em diferenças morfológicas, fisiológicas e moleculares. Entre os métodos preditivos, a análise de agrupamento destaca-se, pois apresenta a finalidade de reunir, por algum critério de classificação, os genitores em grupos, de tal forma que exista homogeneidade dentro do grupo e heterogeneidade entre os grupos, sendo adequada para identificar os genótipos divergentes e com maior probabilidade de sucesso nos cruzamentos.

A medida de dissimilaridade e o método de agrupamento utilizado devem garantir ao melhorista segurança na seleção de genitores para os cruzamentos. CRUZ \& REGAZZI (1997) e MINGOTI (2005) salientam que diversos métodos com base em diferentes medidas de dissimilaridade podem levar a distintos padrões de agrupamento. Comparações entre algumas medidas de dissimilaridade têm sido realizadas em estudos de divergência genética em milho (CRUZ, 1990), em feijão-vagem (Phaseolus vulgaris L.) (MALUF \& FERREIRA, 1983) e em aveia (BENIN et al., 2003), revelando em alguns casos concordâncias e em outros discordâncias. Tal concordância ou discordância é dependente da magnitude das correlações residuais que possam existir entre os caracteres considerados (CRUZ, 1990). A distância generalizada de Mahalanobis entre os pares de genótipos é adequada e amplamente utilizada como medida de dissimilaridade nos métodos de agrupamento, com dados provenientes de experimentos com repetições (CRUZ \& REGAZZI, 1997; CRUZ \& CARNEIRO, 2003), sendo que ela considera a existência de correlações entre os caracteres analisados por meio da matriz de variâncias e covariâncias residuais.

O agrupamento, com base nos métodos hierárquico de Ward e otimização de Tocher, tem sido comum em estudos de divergência genética. Além desses, outros métodos de agrupamento têm sido comparados em acessos das espécies Paspalum guenoarum e Paspalum plicatulum (TOTTI et al., 2001), em acessos de tomateiro (KARASAWA et al., 2005), em pimentas e pimentões (SUDRÉ et al., 2005), em espécies florestais (ALBUQUERQUE et al., 2006), em genótipos de trigo (BERTAN et al., 2006) e em cultivares crioulas de feijão (BONETT et al., 2006), revelando, de maneira geral, distintos níveis de concordância.

Presença de interação cultivares $\times$ ambientes é esperada em experimentos conduzidos em diferentes locais, anos e épocas de cultivo. Então, a inclusão de novos ambientes (locais, anos e épocas) poderá alterar o agrupamento das cultivares, independentemente da medida de dissimilaridade e do método de agrupamento utilizado. Assim, a identificação de cultivares divergentes, por meio de análise de agrupamento, com base em apenas um experimento, poderá ser pouco eficiente devido à variabilidade de resposta das cultivares frente às condições ambientais. Portanto, é importante determinar o número de ambientes (experimentos) necessários para a identificação de cultivares divergentes, por meio de análise de agrupamento, pois esta quantificação não é conhecida para a cultura do feijão.

Assim, o objetivo deste trabalho foi determinar o número de ambientes (experimentos) necessários para a identificação de cultivares de feijão (Phaseolus vulgaris L.) divergentes, por meio dos métodos de agrupamento - hierárquico de Ward e otimização de Tocher - com base em características de produção, fenologia e morfologia, na região da depressão central do Estado do Rio Grande do Sul.

\section{MATERIAL E MÉTODOS}

Treze cultivares de feijão ("Carioca”, “Diamante Negro”, “TPS Nobre”, “Guapo Brilhante”, “Guateian 6662”, “Iapar 44”, “Macanudo”, “Macotaço”, “Minuano”, "Pérola”, "Rio Tibagi”, “TPS Bionobre" e "TPS Bonito") foram avaliadas em nove experimentos conduzidos no delineamento aleatorizado em blocos, com três repetições, na Universidade Federal de Santa Maria, Santa Maria, Rio Grande do Sul (latitude $29^{\circ} 42 \mathrm{~S}$, longitude $53^{\circ} 49 \mathrm{~W}$ e $95 \mathrm{~m}$ de altitude). As parcelas foram compostas de quatro fileiras de $4 \mathrm{~m}$ de comprimento, espaçadas de 0,50m, e a área útil de $3 \mathrm{~m}^{2}$. A densidade de semeadura foi ajustada de acordo com o hábito de crescimento de cada cultivar (CEPEF, 2003). Os experimentos foram conduzidos nos anos agrícolas 2000/2001, 2001/2002, 2002/2003, 2003/2004 e 2004/2005, em duas épocas de cultivo: safra (semeadura em setembro ou outubro) e safrinha (semeadura em janeiro ou fevereiro). O solo foi preparado de maneira convencional e a adubação foi realizada de acordo com a interpretação da análise química do solo. O controle de insetos foi efetuado com a aplicação de Metamidofós e o controle de plantas invasoras foi manual e efetuado sempre que necessário, de maneira que a cultura não sofresse competição.

Em cada experimento, foram avaliados os caracteres produtividade de grãos a 13\% de umidade, número de vagens por planta e de sementes por vagem, massa de cem grãos, população final de plantas, número de dias da emergência ao florescimento e da emergência 
à colheita, altura de inserção de primeira vagem e de última vagem e grau de acamamento (escala de notas entre um e nove, sendo 1 = planta ereta e $9=$ planta acamada).

Neste estudo foi considerado como primeiro experimento o cultivo de safra realizado no ano 2000/ 2001 e o segundo experimento foi considerado o cultivo de safrinha de 2001 e assim sucessivamente até o nono experimento realizado em cultivo de safra no ano 2004/ 2005 (Tabela 1).

A análise de variância individual do experimento 1 foi realizada, assim como a análise de variância conjunta dos dois primeiros (1 e 2), três primeiros (1, 2 e 3), e assim sucessivamente até os nove primeiros (1, 2, 3, 4, 5, 6, 7, 8 e 9) experimentos, e teste $F$ a $5 \%$ de probabilidade. O efeito de cultivar foi considerado fixo e os efeitos de bloco e de ambiente (experimento) foram considerados como aleatórios. $\mathrm{Na}$ análise conjunta, para os caracteres com relação entre os quadrados médios residuais dos ambientes (experimentos) maior que sete (GOMES, 1990; CRUZ \& REGAZZI, 1997), foi realizada a correção dos graus de liberdade (CRUZ, 2001).

As nove matrizes de distância generalizada de Mahalanobis $\left(\mathrm{D}^{2}\right)$ entre as cultivares foram determinadas: matriz 1: obtida com o primeiro

Tabela 1 - Valores do teste F da análise de variância dos caracteres produtividade de grãos, em kg ha-1 (PROD), número de vagens por planta (NVP), número de sementes por vagem (NSV), massa de cem grãos, em g (MCG), população final de plantas, em plantas 3m (POP), número de dias da emergência ao florescimento (FLOR), número de dias da emergência à colheita (CICLO), altura de inserção da primeira vagem, em cm (APV), altura de inserção da última vagem, em cm (AUV), e grau de acamamento ${ }^{(1)}$ (ACA), de 13 cultivares de feijão, avaliadas em nove experimentos ${ }^{(2)}$, em relação às fontes de variação cultivares, aos experimentos e à interação cultivares $\times$ experimentos.

\begin{tabular}{|c|c|c|c|c|c|c|c|c|c|c|}
\hline $\begin{array}{l}\text { Experimentos envolvidos na } \\
\text { análise de variância }\end{array}$ & PROD & NVP & NSV & MCG & POP & FLOR & CICLO & APV & AUV & ACA \\
\hline & & \multicolumn{9}{|c|}{ 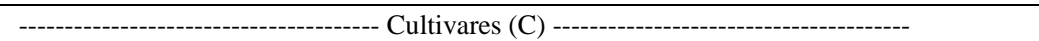 } \\
\hline 1 & $5,7 *$ & $2,3^{*}$ & $1,0^{\mathrm{ns}}$ & $8,0^{*}$ & $1,3^{\mathrm{ns}}$ & $16,9 *$ & $24,6^{*}$ & $9,2 *$ & $3,6^{*}$ & $3,0 *$ \\
\hline 1 e 2 & $9,1^{*}$ & $3,8^{*}$ & $1,8^{\mathrm{ns}}$ & $5,2^{*}$ & $1,4^{\mathrm{ns}}$ & $13,2^{*}$ & $1,8^{\mathrm{ns}}$ & $4,9 *$ & $2,4^{\mathrm{ns}}$ & $4,2 *$ \\
\hline 1,2 e 3 & $9,2 *$ & $2,9 *$ & $1,8^{\mathrm{ns}}$ & $8,3^{*}$ & $1,6^{\mathrm{ns}}$ & $5,6^{*}$ & $3,3^{*}$ & $3,0 *$ & $3,0 *$ & $6,7^{*}$ \\
\hline $1,2,3$ e 4 & $8,7^{*}$ & $4,6^{*}$ & $3,4^{*}$ & $7,1^{*}$ & $1,4^{\mathrm{ns}}$ & $4,0^{*}$ & $4,0^{*}$ & $3,3 *$ & $4,3 *$ & $7,8^{*}$ \\
\hline $1,2,3,4$ e 5 & $5,8^{*}$ & $5,8^{*}$ & $3,4^{*}$ & $9,8^{*}$ & $1,5^{\mathrm{ns}}$ & $3,2 *$ & $5,0^{*}$ & $3,3 *$ & $2,2 *$ & $10,2^{*}$ \\
\hline $1,2,3,4,5$ e 6 & $3,6^{*}$ & $5,6^{*}$ & $3,3^{*}$ & $8,4^{*}$ & $2,1^{*}$ & $3,5^{*}$ & $4,7^{*}$ & $2,9 *$ & $2,1 *$ & $10,3^{*}$ \\
\hline $1,2,3,4,5,6$ е 7 & $3,6^{*}$ & $5,8^{*}$ & $4,0 *$ & $10,8^{*}$ & $2,5^{*}$ & $3,9 *$ & $5,4^{*}$ & $2,9 *$ & $2,9 *$ & $12,1^{*}$ \\
\hline $1,2,3,4,5,6,7$ e 8 & $3,5^{*}$ & $4,3^{*}$ & $4,5^{*}$ & $12,4^{*}$ & $2,0^{*}$ & $4,6^{*}$ & $5,8^{*}$ & $2,6 *$ & $4,1^{*}$ & $12,2^{*}$ \\
\hline \multirow[t]{2}{*}{$1,2,3,4,5,6,7,8$ е 9} & $4,1^{*}$ & $4,8^{*}$ & $4,1^{*}$ & $12,9 *$ & $2,7^{*}$ & $5,5^{*}$ & $6,9 *$ & $2,9 *$ & $5,1^{*}$ & $14,6^{*}$ \\
\hline & & & & & -- Experi & entos (E) & --------- & ------- & --------- & \\
\hline 1 & - & - & - & - & - & - & - & - & - & - \\
\hline 1 e 2 & $299,3^{*}$ & $0,0^{\mathrm{ns}}$ & $100,9 *$ & $242,0 *$ & $2,6^{\mathrm{ns}}$ & $320,4^{*}$ & $2,9^{\mathrm{ns}}$ & $0,4^{\mathrm{ns}}$ & $0,0^{\mathrm{ns}}$ & $7,1^{\mathrm{ns}}$ \\
\hline 1,2 e 3 & $6,2^{*}$ & $7,5^{*}$ & $27,9 *$ & $6,1^{*}$ & $3,8^{\mathrm{ns}}$ & $16,6^{*}$ & $1,9^{\mathrm{ns}}$ & $0,5^{\mathrm{ns}}$ & $3,3^{\mathrm{ns}}$ & $1,8^{\mathrm{ns}}$ \\
\hline $1,2,3$ e 4 & $8,6^{*}$ & $7,8^{*}$ & $25,6^{*}$ & $5,9^{*}$ & $2,8^{\mathrm{ns}}$ & $15,8^{*}$ & $2,4^{\mathrm{ns}}$ & $4,8^{*}$ & $4,2^{*}$ & $1,6^{\mathrm{ns}}$ \\
\hline $1,2,3,4$ e 5 & $8,6^{*}$ & $6,9 *$ & $23,3^{*}$ & $8,0^{*}$ & $3,1^{\mathrm{ns}}$ & $15,3^{*}$ & $3,1^{\mathrm{ns}}$ & $8,4^{*}$ & $33,5^{*}$ & $2,2^{\mathrm{ns}}$ \\
\hline $1,2,3,4,5$ е 6 & $13,5^{*}$ & $10,1^{*}$ & $24,7 *$ & $41,9 *$ & $3,2^{*}$ & $38,6 *$ & $7,0^{*}$ & $7,9 *$ & $99,6^{*}$ & $7,7 *$ \\
\hline $1,2,3,4,5,6$ e 7 & $14,7^{*}$ & $10,6^{*}$ & $23,8 *$ & $41,4^{*}$ & $3,5^{*}$ & $57,8^{*}$ & $9,4^{*}$ & $8,2^{*}$ & $85,7 *$ & $6,5^{*}$ \\
\hline $1,2,3,4,5,6,7$ e 8 & $15,2^{*}$ & $10,6^{*}$ & $27,6^{*}$ & $43,7^{*}$ & $3,6^{*}$ & $55,2 *$ & $9,2^{*}$ & $7,9 *$ & $63,2 *$ & $12,1^{*}$ \\
\hline \multirow[t]{2}{*}{$1,2,3,4,5,6,7,8$ е 9} & $15,4^{*}$ & $11,1^{*}$ & $32,1^{*}$ & $44,8^{*}$ & $3,9 *$ & $62,9 *$ & $18,7^{*}$ & $11,3^{*}$ & $70,6^{*}$ & $12,9 *$ \\
\hline & & & & & ---- & $F$ & & & ---- & \\
\hline 1 & - & - & - & - & - & - & - & - & - & - \\
\hline 1 e 2 & $1,2^{\mathrm{ns}}$ & $2,2 *$ & $0,8^{\mathrm{ns}}$ & $2,2 *$ & $0,8^{\mathrm{ns}}$ & $2,2 *$ & $14,5^{*}$ & $1,7^{\mathrm{ns}}$ & $1,9^{\mathrm{ns}}$ & $1,8^{\mathrm{ns}}$ \\
\hline 1,2 e 3 & $1,0^{\mathrm{ns}}$ & $2,7^{*}$ & $1,1^{\mathrm{ns}}$ & $1,6^{\mathrm{ns}}$ & $1,2^{\mathrm{ns}}$ & $3,1^{*}$ & $8,4^{*}$ & $2,7 *$ & $1,9 *$ & $1,1^{\mathrm{ns}}$ \\
\hline $1,2,3$ е 4 & $1,3^{\mathrm{ns}}$ & $2,1^{*}$ & $1,0^{\mathrm{ns}}$ & $1,8^{*}$ & $1,1^{\mathrm{ns}}$ & $3,4^{*}$ & $8,1^{*}$ & $2,3^{*}$ & $1,6^{*}$ & $1,0^{\mathrm{ns}}$ \\
\hline $1,2,3,4$ e 5 & $2,8^{*}$ & $2,0^{*}$ & $1,0^{\mathrm{ns}}$ & $1,7^{*}$ & $1,2^{\mathrm{ns}}$ & $4,5^{*}$ & $8,1^{*}$ & $2,6^{*}$ & $2,6^{*}$ & $1,0^{\mathrm{ns}}$ \\
\hline $1,2,3,4,5$ e 6 & $3,1^{*}$ & $2,1^{*}$ & $0,9^{\mathrm{ns}}$ & $1,6^{*}$ & $1,2^{\mathrm{ns}}$ & $4,0^{*}$ & $7,8^{*}$ & $2,5^{*}$ & $2,4^{*}$ & $1,4^{\mathrm{ns}}$ \\
\hline $1,2,3,4,5,6$ e 7 & $3,0^{*}$ & $2,0^{*}$ & $0,9^{\mathrm{ns}}$ & $1,6^{*}$ & $1,2^{\mathrm{ns}}$ & $4,1^{*}$ & $7,6^{*}$ & $2,6^{*}$ & $2,3^{*}$ & $1,5^{*}$ \\
\hline $1,2,3,4,5,6,7$ e 8 & $3,1^{*}$ & $2,3^{*}$ & $0,9^{\mathrm{ns}}$ & $1,6^{*}$ & $1,5^{\mathrm{ns}}$ & $4,0 *$ & $8,7^{*}$ & $2,7 *$ & $2,3 *$ & $1,6^{*}$ \\
\hline $1,2,3,4,5,6,7,8$ е 9 & $3,2 *$ & $2,3 *$ & $1,0^{\mathrm{ns}}$ & $1,7^{*}$ & $1,5^{*}$ & $3,9 *$ & $8,6^{*}$ & $2,8 *$ & $2,2 *$ & $1,7^{*}$ \\
\hline
\end{tabular}

${ }^{(1)}$ Escala de notas entre um a nove (1 = planta ereta; 9 = planta acamada). ${ }^{(2)}$ 1) Safra-2000/2001, 2) Safrinha-2001, 3) Safra-2001/2002, 4) Safrinha-2002, 5) Safra-2002/2003, 6) Safrinha-2003, 7) Safra-2003/2004, 8) Safrinha-2004 e 9) Safra-2004/2005. * Significativo a 5\% de probabilidade pelo teste $\mathrm{F},{ }^{\text {ns }}$ Não-significativo. 
experimento (1), matriz 2: obtida com os dois primeiros experimentos (1 e 2), ..., matriz 9: obtida com os nove experimentos. Essas matrizes, em escala relativa, foram utilizadas como medida de dissimilaridade para a análise de agrupamento das cultivares pelos métodos hierárquico de Ward e otimização de Tocher (CRUZ \& REGAZZI, 1997; CRUZ, 2001; CRUZ \& CARNEIRO, 2003).

O coeficiente de correlação de Pearson entre as nove matrizes $\mathrm{D}^{2}$ foi calculado e sua significância foi verificada pelo teste $\mathrm{t}$ de Student a $5 \%$ de probabilidade de erro. As análises estatísticas foram realizadas no programa GENES (CRUZ, 2001).

\section{RESULTADOS E DISCUSSÃO}

A análise de variância conjunta em relação a todos os caracteres, com exceção do número de sementes por vagem (NSV), apresentou interação cultivares $\times$ ambientes (experimentos) significativa em pelo menos um dos oito casos analisados (dois, três, ..., nove experimentos), o que revela comportamento diferencial das cultivares de feijão nos ambientes (Tabela 1). Esses resultados sugerem que o agrupamento de cultivares realizado com base em apenas uma época de cultivo (um experimento) pode fornecer informações equivocadas por não considerar a variabilidade ambiental entre anos e épocas de cultivo, dentro de um mesmo local. BERTAN et al. (2006) afirmaram que a significância do efeito de cultivares $\times$ ambientes revela a necessidade de avaliação das cultivares em mais que um ambiente (local, ano ou época de cultivo), sendo tão mais segura quanto maior for o número de ambientes considerados.

O teste $\mathrm{F}$, da análise de variância individual (apenas 1 experimento) e conjunta (demais oito casos dois, três, ..., nove experimentos), revelou efeito de cultivares significativo em relação a todos os caracteres, com algumas exceções quanto aos caracteres número de sementes por vagem (NSV), população final de plantas (POP), número de dias da emergência à colheita (CICLO) e altura de inserção da última vagem (AUV), possibilitando, de maneira geral, a identificação de cultivares superiores devido à heterogeneidade do germoplasma (Tabela 1) e à formação de grupos (Figura 1 e Tabela 2).

Entre experimentos, o teste $\mathrm{F}$, da análise de variância conjunta (oito casos), revelou efeito significativo em relação aos caracteres produtividade de grãos (PROD), número de sementes por vagem (NSV), massa de cem grãos (MCG) e número de dias da emergência ao florescimento (FLOR). Já em relação aos caracteres número de vagens por planta (NVP), população final de plantas (POP), número de dias da emergência à colheita (CICLO), altura de inserção da primeira vagem (APV), altura de inserção da última vagem (AUV) e grau de acamamento (ACA), em alguns casos, não houve efeito de experimentos.

De maneira geral, a significância dos efeitos de interação cultivares $\times$ ambientes (experimento), de cultivares e de experimentos, para a maioria dos caracteres e dos oito casos analisados (dois, três, ..., nove experimentos envolvidos na análise) revelaram a possibilidade de identificar cultivares divergentes por meio de agrupamento e formação de distintos agrupamentos de acordo com o número de ambientes envolvidos na análise. Nesse sentido, a investigação do número mínimo necessário de ambientes (experimentos) para o agrupamento é particularmente importante na confiabilidade da seleção daquelas cultivares divergentes para serem utilizadas em cruzamentos controlados.

Em um dendrograma, grande mudança de nível na distância de agrupamento indica a união de cultivares heterogêneas (BARROSO \& ARTES, 2003). Assim, utilizando-se $60 \%$ de similaridade como critério para definição dos grupos, pelo método de Ward, houve formação de três grupos idênticos de cultivares com base em sete, oito ou nove experimentos (Figura 1). Já o método de Tocher, separou as cultivares em quatro grupos idênticos a partir da análise de agrupamento com base em seis experimentos (Tabela 2). Esses resultados evidenciam que a inclusão de mais experimentos, a partir do sétimo e sexto, respectivamente, para os métodos de Ward e de Tocher, não altera o padrão de agrupamento das cultivares, ou seja, o efeito da interação cultivares $\times$ experimentos não modifica o agrupamento. Resultados semelhantes foram obtidos por CARGNELUTTI FILHO et al. (2006), os quais revelaram que, na região da depressão central do Estado do Rio Grande do Sul, sete experimentos são suficientes para identificar cultivares de feijão superiores em relação às características de produção, de fenologia e de morfologia, com 85\% de exatidão no prognóstico de seu valor real.

Os coeficientes de correlação linear (r) significativos e de alta magnitude $(r \geq 0,93)$ entre as matrizes $\mathrm{D}^{2}$ com base em seis, sete, oito e nove experimentos explicaram a concordância nos agrupamentos (Tabela 3). Portanto, os resultados evidenciaram que sete e seis experimentos são suficientes para identificar as cultivares divergentes, por meio de análise de agrupamento, a partir dos métodos de Ward e de Tocher, respectivamente. No entanto, antes dessas considerações serem 


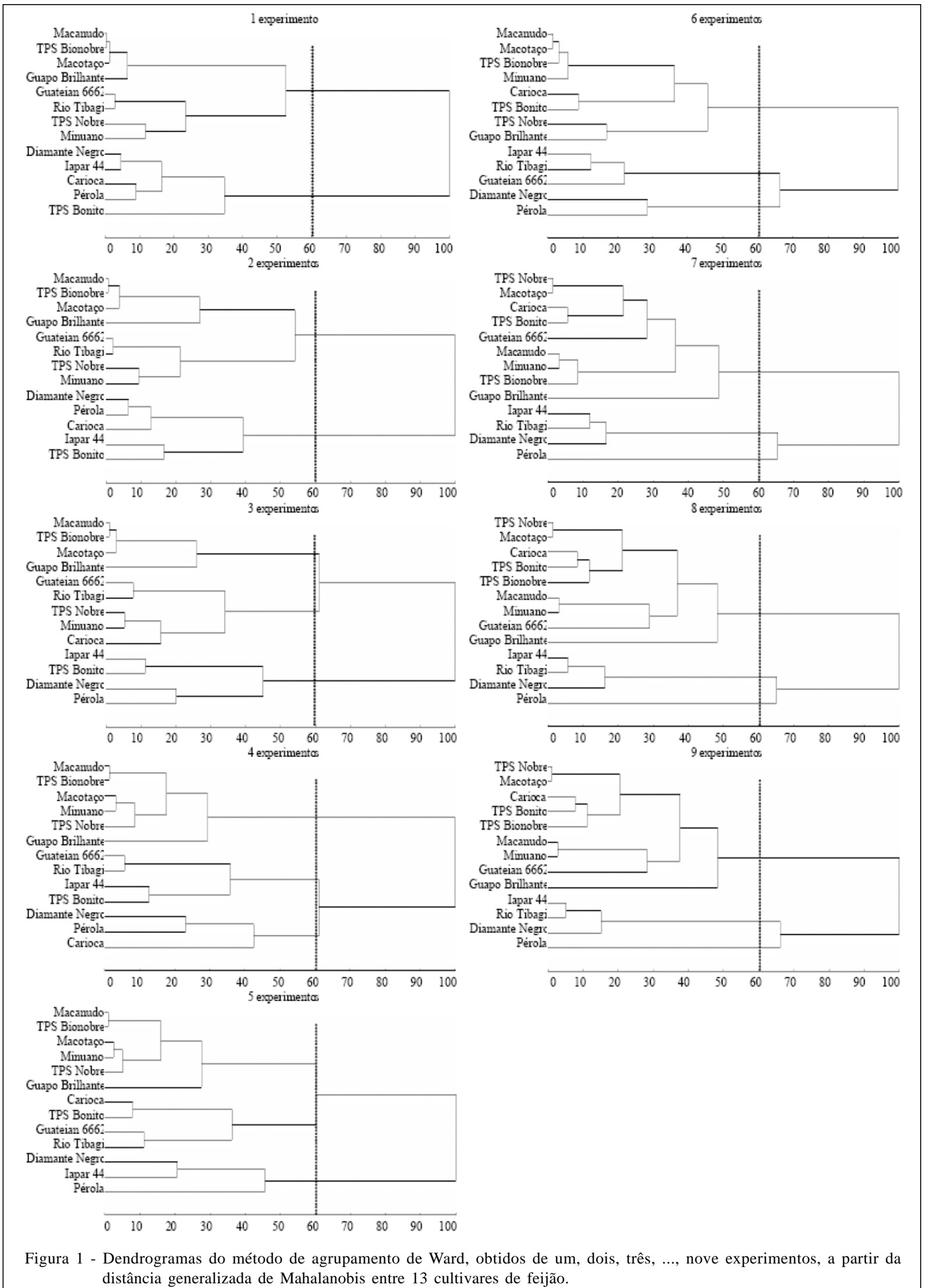

Ciência Rural, v.39, n.2, mar-abr, 2009. 
Tabela 2 - Cultivares em cada grupo obtido pelo método de otimização de Tocher a partir da distância generalizada de Mahalanobis, entre 13 cultivares de feijão, avaliadas em nove experimentos ${ }^{(1)}$.

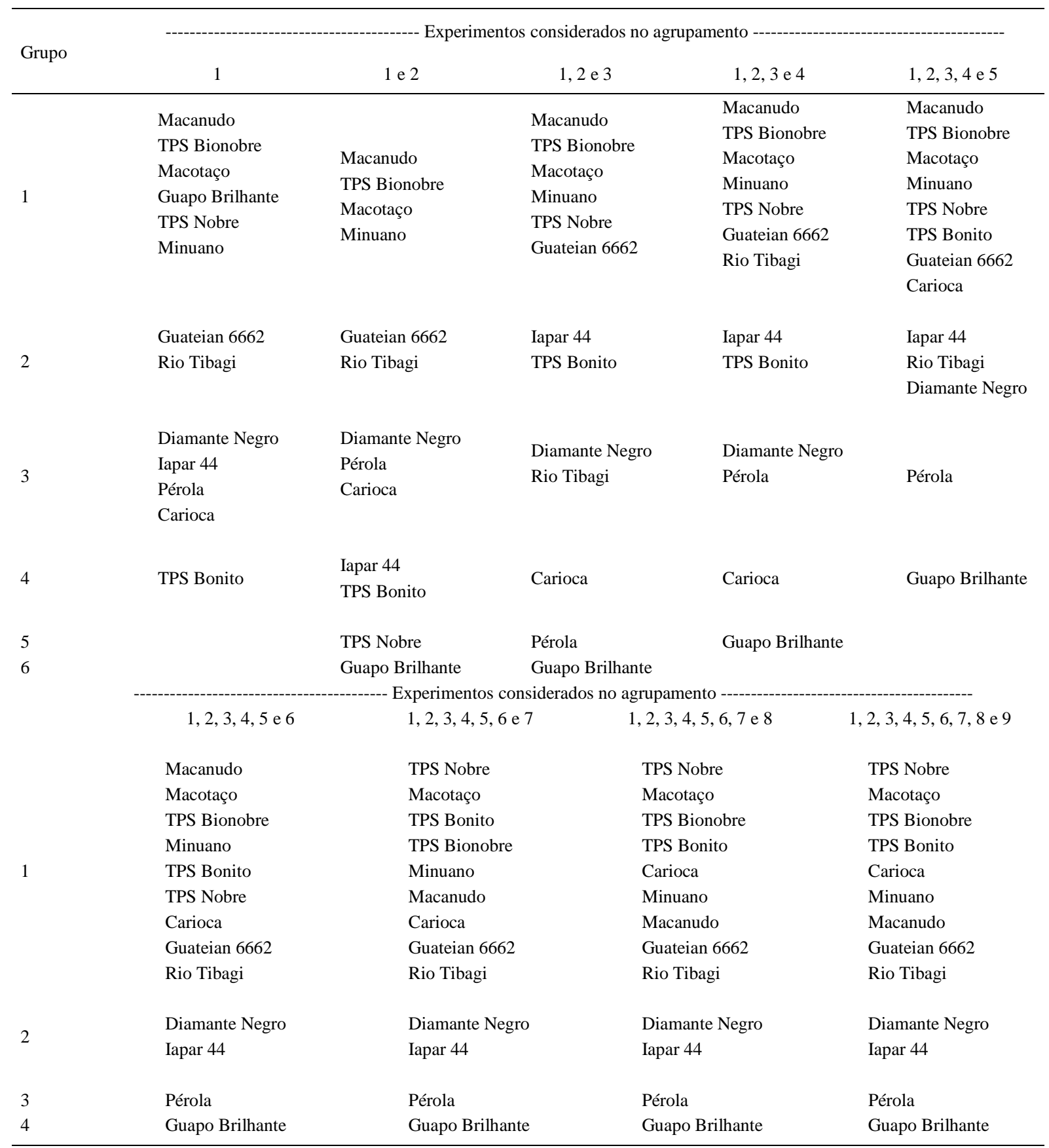

(1) 1) Safra-2000/2001, 2) Safrinha-2001, 3) Safra-2001/2002, 4) Safrinha-2002, 5) Safra-2002/2003, 6) Safrinha-2003, 7) Safra-2003/2004, 8) Safrinha-2004 e 9) Safra-2004/2005.

generalizadas para experimentos com feijão, há necessidade de investigar outros métodos de agrupamento, outras medidas de dissimilaridade, outras cultivares e outras variáveis usadas para o agrupamento. Além disso, trabalho com simulação de dados, envolvendo maior número de experimentos, com diferentes padrões de interação genótipos $\times$ ambientes (simples, complexas e misturas dos dois) é importante e adequado antes de generalizar essas informações. Também, em outras culturas o número necessário de experimentos para a análise de agrupamento pode ser diferente.

Ciência Rural, v.39, n.2, mar-abr, 2009. 
Tabela 3 - Coeficiente de correlação entre as nove matrizes (matriz 1: obtida com o primeiro experimento, matriz 2: obtida com os dois primeiros experimentos, ..., matriz 9: obtida com os nove experimentos) de distância generalizada de Mahalanobis ( $\left.\mathrm{D}^{2}\right)$ entre 13 cultivares de feijão, avaliadas em nove experimentos ${ }^{(1)}$.

\begin{tabular}{|c|c|c|c|c|c|c|c|c|}
\hline $\begin{array}{l}\text { Experimentos para } \\
\text { obtenção de } \mathrm{D}^{2}\end{array}$ & 1 e 2 & 1,2 е 3 & $1,2,3$ е 4 & $\begin{array}{c}1,2,3,4 \mathrm{e} \\
5\end{array}$ & $\begin{array}{c}1,2,3,4,5 \text { e } \\
6\end{array}$ & $\begin{array}{c}1,2,3,4 \\
5,6 \text { e } 7\end{array}$ & $\begin{array}{c}1,2,3,4,5,6 \\
7 \text { e } 8\end{array}$ & $\begin{array}{c}1,2,3,4,5,6,7,8 \text { e } \\
9\end{array}$ \\
\hline 1 & $0,92 *$ & $0,80^{*}$ & $0,43^{*}$ & $0,24 *$ & $0,16^{\mathrm{ns}}$ & $0,14^{\mathrm{ns}}$ & $0,10^{\mathrm{ns}}$ & $0,08^{\mathrm{ns}}$ \\
\hline 1 e 2 & & $0,90^{*}$ & $0,57^{*}$ & $0,39 *$ & $0,32 *$ & $0,30 *$ & $0,25 *$ & $0,22^{\mathrm{ns}}$ \\
\hline 1,2 e 3 & & & $0,80 *$ & $0,66^{*}$ & $0,60 *$ & $0,58 *$ & $0,52 *$ & $0,48^{*}$ \\
\hline $1,2,3$ е 4 & & & & $0,94 *$ & $0,91 *$ & $0,87^{*}$ & $0,81^{*}$ & $0,76^{*}$ \\
\hline $1,2,3,4$ e 5 & & & & & $0,98 *$ & $0,97 *$ & $0,93 *$ & $0,89 *$ \\
\hline $1,2,3,4,5$ e 6 & & & & & & $0,99 *$ & $0,96 *$ & $0,93 *$ \\
\hline $1,2,3,4,5,6$ e 7 & & & & & & & $0,98 *$ & $0,96 *$ \\
\hline $1,2,3,4,5,6,7$ e 8 & & & & & & & & $0,99 *$ \\
\hline
\end{tabular}

(1) 1) Safra-2000/2001, 2) Safrinha-2001, 3) Safra-2001/2002, 4) Safrinha-2002, 5) Safra-2002/2003, 6) Safrinha-2003, 7) Safra-2003/2004, 8) Safrinha-2004 e 9) Safra-2004/2005. * Significativo a 5\% de probabilidade, pelo teste t com 76 graus de liberdade. ${ }^{\text {ns }}$ Não-significativo.

A análise de agrupamento realizada com o maior número de ambientes (experimentos) possíveis entre os locais de uma região e, no mesmo local, com o maior número de anos e de épocas de cultivo, é adequada para a melhor tomada de decisão em relação à escolha de cultivares para os cruzamentos controlados. A utilização do número adequado de experimentos que permita o reconhecimento das diferenças entre os genitores com base nos descritores agromorfológicos e que considere os efeitos da interação genótipos $\times$ ambientes, permitirá maior eficiência no planejamento das combinações híbridas a serem obtidas pelo programa de melhoramento. Assim, será possível racionalizar o número de cruzamanentos e obter maior eficácia na seleção de populações segregantes com variabilidade genética superior.

\section{CONCLUSÕES}

Na região da depressão central do Estado do Rio Grande do Sul, sete e seis experimentos são suficientes para identificar cultivares de feijão divergentes, por meio dos métodos de agrupamento hierárquico de Ward e de otimização de Tocher, respectivamente, quanto às características de produção, fenologia e morfologia, com base na distância generalizada de Mahalanobis entre as cultivares.

\section{AGRADECIMENTOS}

Ao Conselho Nacional de Desenvolvimento Científico e Tecnológico (CNPq), pela concessão de bolsa de Produtividade em Pesquisa para Alberto Cargnelutti Filho e
Nerinéia Dalfollo Ribeiro e de bolsa de Doutorado para Evandro Jost.

\section{REFERÊNCIAS}

ALBUQUERQUE, M.A. et al. Estabilidade em análise de agrupamento: estudo de caso em ciência florestal. Revista Árvore, v.30, p.257-265, 2006.

BARROSO, L.P.; ARTES, R. Análise multivariada. Lavras: UFLA, 2003. 151p.

BENIN, G. et al. Comparações entre medidas de dissimilaridade e estatísticas multivariadas como critérios no direcionamento de hibridações em aveia. Ciência Rural, v.33, p.657-662, 2003.

BERTAN, I. et al. Comparação de métodos de agrupamento na representação da distância morfológica entre genótipos de trigo. Revista Brasileira de Agrociência, v.12, p.279-286, 2006.

BONETT, L.P. et al. Divergência genética em germoplasma de feijoeiro comum coletado no estado do Paraná, Brasil. Semina, v.27, p.547-560, 2006.

CARGNELUTTI FILHO, A. et al. Número necessário de experimentos para a comparação de cultivares de feijão. Ciência Rural, v.36, p.1701-1709, 2006.

COMISSÃO ESTADUAL DE PESQUISA DE FEIJÃO. CEPEF. Indicações técnicas para a cultura do feijão no Rio Grande do Sul 2003/04. Passo Fundo: UPF, 2003. 149p.

CRUZ, C.D.; CARNEIRO, P.C.S. Modelos biométricos aplicados ao melhoramento genético. Viçosa: UFV, 2003. 585p.

CRUZ, C.D.; REGAZZI, A.J. Modelos biométricos aplicados ao melhoramento genético. 2.ed. Viçosa: UFV, 1997. 390p.

CRUZ, C.D. Aplicação de algumas técnicas multivariadas no melhoramento de plantas. 1990. 188f. Tese (Doutorado 
em Agronomia) - Programa de Pós-graduação em Genética e Melhoramento de Plantas, Escola Superior de Agricultura Luiz de Queiroz.

CRUZ, C.D. PROGRAMA GENES: versão Windows: aplicativo computacional em genética e estatística. Viçosa: UFV, 2001. 648p.

GOMES, F.P. Curso de estatística experimental. 13.ed. Piracicaba: São Paulo: Nobel 1990. 468p.

KARASAWA, M. et al. Aplicação de métodos de agrupamento na quantificação da divergência genética entre acessos de tomateiro. Horticultura Brasileira, v.23, p.1000-1005, 2005.
MALUF, W.R.; FERREIRA, P.E. Análise multivariada da divergência genética em feijão-vagem (Phaseolus vulgaris L.). Horticultura Brasileira, v.1, p.31-34, 1983.

MINGOTI, S.A. Análise de dados através de métodos de estatística multivariada. Belo Horizonte: UFMG, 2005. 297p.

SUDRÉ, C.P. et al. Divergência genética entre acessos de pimenta e pimentão utilizando técnicas multivariadas. Horticultura Brasileira, v.23, p.22-27, 2005.

TOTTI, R. et al. Utilização de métodos de agrupamentos hierárquicos em acessos de Paspalum (Graminea (Poaceae)). Semina, v.22, p.25-35, 2001. 